\title{
Masseteric-facial nerve neurorrhaphy: results of a case series
}

\author{
Federico Biglioli, MD, ${ }^{1}$ Valeria Colombo, MD,, Dimitri Rabbiosi, MD, ${ }^{1}$ Filippo Tarabbia, MD, ${ }^{1}$ \\ Federica Giovanditto, MD, ${ }^{1}$ Alessandro Lozza, MD, ${ }^{2}$ Silvia Cupello, PhD, ${ }^{3}$ and Pietro Mortini, MD ${ }^{4}$
}

Departments of ${ }^{1}$ Maxillo-Facial Surgery and ${ }^{3}$ Physiotherapy, San Paolo Hospital, University of Milan; ${ }^{2}$ Neurophysiopathology Service, C. Mondino National Neurological Institute, Pavia; and ${ }^{4}$ Department of Neurosurgery, San Raffaele Hospital, University Vita e Salute, Milan, Italy

OBJECTIVE Facial palsy is a well-known functional and esthetic problem that bothers most patients and affects their social relationships. When the time between the onset of paralysis and patient presentation is less than 18 months and the proximal stump of the injured facial nerve is not available, another nerve must be anastomosed to the facial nerve to reactivate its function. The masseteric nerve has recently gained popularity over the classic hypoglossus nerve as a new motor source because of its lower associated morbidity rate and the relative ease with which the patient can activate it. The aim of this work was to evaluate the effectiveness of masseteric-facial nerve neurorrhaphy for early facial reanimation.

METHODS Thirty-four consecutive patients (21 females, 13 males) with early unilateral facial paralysis underwent masseteric-facial nerve neurorrhaphy in which an interpositional nerve graft of the great auricular or sural nerve was placed. The time between the onset of paralysis and surgery ranged from 2 to 18 months (mean 13.3 months). Electromyography revealed mimetic muscle fibrillations in all the patients. Before surgery, all patients had House-Brackmann Grade VI facial nerve dysfunction. Twelve months after the onset of postoperative facial nerve reactivation, each patient underwent a clinical examination using the modified House-Brackmann grading scale as a guide.

RESULTS Overall, $91.2 \%$ of the patients experienced facial nerve function reactivation. Facial recovery began within 2-12 months (mean 6.3 months) with the restoration of facial symmetry at rest. According to the modified House-Brackmann grading scale, $5.9 \%$ of the patients had Grade I function, $61.8 \%$ Grade II, $20.6 \%$ Grade III, $2.9 \%$ Grade V, and $8.8 \%$ Grade VI. The morbidity rate was low; none of the patients could feel the loss of masseteric nerve function. There were only a few complications, including 1 case of postoperative bleeding (2.9\%) and 2 local infections (5.9\%), and a few patients complained about partial loss of sensitivity of the earlobe or a small area of the ankle and foot, depending on whether great auricular or sural nerves were harvested.

CONCLUSIONS The surgical technique described here seems to be efficient for the early treatment of facial paralysis and results in very little morbidity.

http://thejns.org/doi/abs/10.3171/2015.12.JNS14601

KEY WORDS facial paralysis; facial reanimation; masseteric-facial nerve neurorrhaphy; facial nerve; masseteric nerve; peripheral nerve

$\mathrm{F}$ ACIAL palsy is a well-known pathological condition that leaves patients with heavy functional and aesthetic burdens. The main functional problem is the loss of corneal coverage and lubrication, which leads to corneal lesions and, in the worst cases, impaired vision. Aesthetically, ptosis of tissues at rest may result in facial asymmetry, which is worsened when patients activate mimetic musculature. So, in many cases, patients stop smiling and cover their face with their hand while talking.

Facial palsies can be a consequence of, for example, tumor removal, Bell's palsy, or trauma. When the facial nerve is injured during surgery, immediate reconstruction of the facial nerve by direct neurorrhaphy between the 2 stumps or by an interpositional nerve graft should be the first option. . $15,20,23,25,29$ In most cases, the proximal stump is not available, and a donor motor nerve is required.

The reconstructive surgical strategy depends much more on the time elapsed since the onset of paralysis than on the etiology of the facial palsy. When that time is less than 18 months, and fibrillations of mimetic musculature 
are still visible by electromyography (EMG), a new motor nerve must be anastomosed to the facial nerve to reactivate its function. That motor nerve has classically been the hypoglossus, which is a very powerful and reliable nerve when used fully. ${ }^{22}$ However, the associated morbidity is not negligible in terms of chewing, speech impairments, and deglutition. ${ }^{32}$ When the hypoglossus is used with an end-to-side neurorrhaphy, morbidity related to the use of this nerve is reduced, but efficacy also decreases. ${ }^{30}$

The masseteric nerve recently gained popularity over the hypoglossal nerve as a new motor nerve source because of its lower associated morbidity rate and greater ease of activation for the patient. ${ }^{1,6,8,13}$ The masseteric nerve is a branch of the trigeminus; thus, its integrity must be ascertained before surgery, and no further surgery that may impair its function should be planned.

In 2012, Biglioli et al. ${ }^{6}$ reported the first case series of patients who underwent anastomosis of the masseteric nerve to the trunk of the facial nerve. The aim of the work described here was to analyze, by retrospective clinical evaluation, the effectiveness of this technique when applied to a large group of consecutive patients.

\section{Methods}

\section{Surgical Technique}

Epinephrine (1:200,000 dilution) is injected subcutaneously into the parotid region and along the drawn-on skin-incision line approximately 5 minutes before surgery. We use a face-lift type of incision that begins in the temporal region and passes hidden behind the tragus, under the earlobe, and extends posteriorly to the earlobe or into a cervical scar, if present from a previous operation (Fig. 1).

When it has been established as the one to be used as the donor, the great auricular nerve is the first to be identified. The great auricular nerve is immediately deep to the superficial cervical fascia, $4-5 \mathrm{~cm}$ caudal to the earlobe, and over the anterior border of the sternocleidomastoid muscle. The nerve is traced caudally for a few centimeters and cranially until its entrance into the parotid gland; 5-6 $\mathrm{cm}$ of the main trunk is taken for use as an interposition nerve graft. When the sural nerve is chosen for grafting, a separate surgical team harvests it in the standard way.

Then, the facial nerve is identified and traced from the stylomastoid foramen by the standard extracranial anterograde technique. The entire nerve trunk and the first $2 \mathrm{~cm}$ of the main branches after bifurcation are exposed. The masseteric motor nerve in the muscle parenchyma is identified. The surgical landmarks are the zygomatic arch and the posterior border of the masseter muscle. Detachment of the muscle insertion in the zygomatic arch is not necessary, because the masseteric nerve is deep at this level and difficult to use for subsequent neurorrhaphy. It is best to enter the muscle $1 \mathrm{~cm}$ above the arch and $1 \mathrm{~cm}$ anterior to its posterior border. The cranial branches of the facial nerve may be seen over the masseter surface, and they must be spared by gently pulling them apart, which makes it possible to deepen the approach into the masseter by cutting its fibers carefully and progressively, being careful not to sever the masseteric nerve deeper in the muscle. The nerve lies $1.5-$ to $2.0-\mathrm{cm}$ deep from the muscle surface and is clearly visible by gently dissecting the muscle fibers

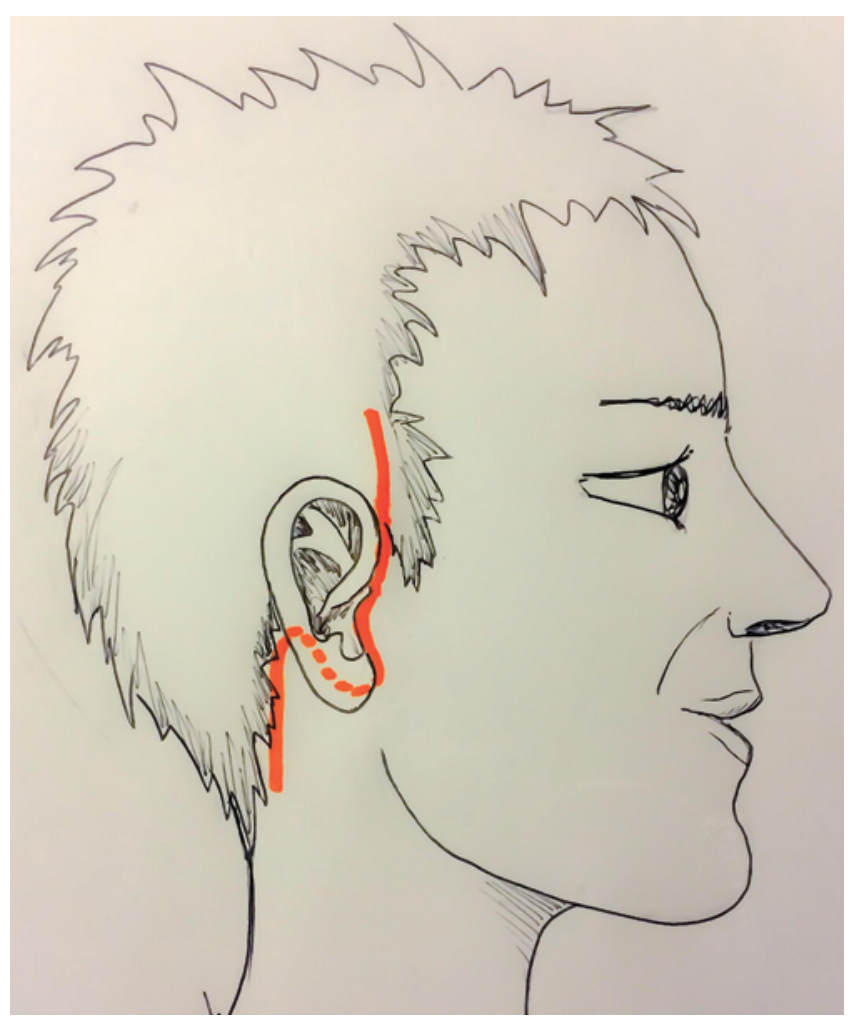

FIG. 1. Face-lift-type incision. Copyright Valeria Colombo. Published with permission. Figure is available in color online only.

along their axis. These muscle fibers ravel easily during dissection, whereas the nerve appears spontaneously.

Next, the masseteric nerve is cut distally, and the facial nerve trunk is severed at its exit from the stylomastoid foramen. Both nerves are transposed to match each other. The few centimeters of distance between their extremities are filled by the interposition graft of the great auricular or sural nerve. They are set in a reversed position so that as few axonal fibers as possible are lost during their growth through the graft. The proximal and distal neurorrhaphies are performed in an end-to-end manner with a few epineural 10-0 stitches surrounded by fibrin glue.

If a cross-face nerve graft is added to enable spontaneous smiling, the sural nerve is used in the following manner. Through standard face-lift access, a branch of the healthy contralateral facial nerve of the great zygomatic muscle is identified and tested by electrostimulation (no curare is delivered to the patient). The branch is anastomosed end-to-end to the sural nerve, previously settled subcutaneously in a reversed position. The end of the sural nerve is then anastomosed end-to-side to a similar branch of the paralyzed facial nerve of the great zygomatic muscle (Fig. 2). ${ }^{31}$

The parotid fascia is placed over the masseteric-facial nerve neurorrhaphy to protect the whole nerve route from later ancillary procedures. Meticulous hemostasis and positioning of a suction drain are mandatory. Finally, a wellhidden aesthetic suture is placed at the end of the surgery.

\section{Case Series}

Between October 2007 and March 2013, 51 consecutive 


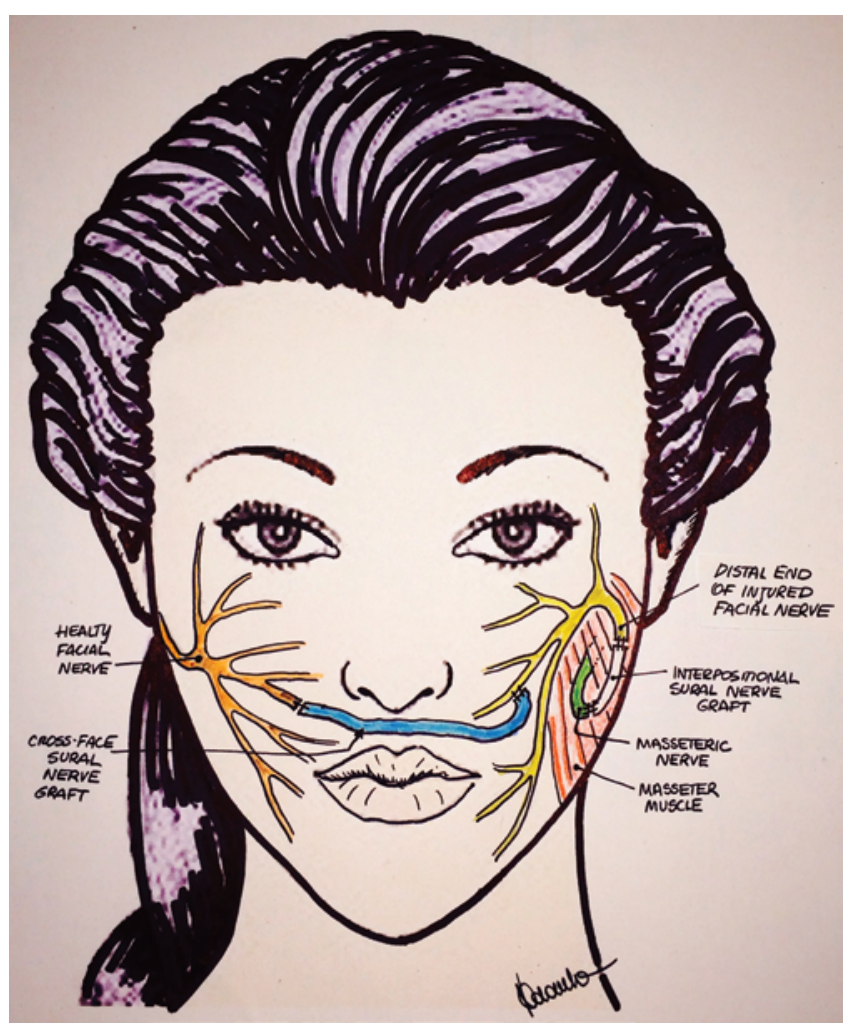

FIG. 2. Drawing of the proposed surgical technique. The masseteric nerve (light green) is anastomosed to the trunk of the facial nerve (light yellow) by a $5-\mathrm{cm}$ nerve graft (white). A cross-face sural nerve graft (light blue) is positioned subcutaneously to join the facial nerve branch for the great zygomatic muscle on the healthy side (end-to-end anastomosis) with the one on the paralyzed side (end-to-side anastomosis). Copyright Valeria Colombo. Published with permission. Figure is available in color online only.

patients (20 males, 31 females) affected by complete unilateral facial paralysis underwent masseteric-facial nerve neurorrhaphy with an interposition nerve graft. Only patients with a minimum follow-up of 12 months after the first signs of muscle function recovery were considered for the study, which resulted in a population of 34 patients (21 females, 13 males). The time between the onset of paralysis and surgery ranged from 2 to 18 months (mean 13.3 months). Patients were between 17 and 77 years of age (mean 45.8 years).

All the palsies were Grade VI according to the HouseBrackmann scale (complete facial nerve deficit). ${ }^{14}$ All patients underwent preoperative needle EMG, which revealed complete facial nerve injury and muscle fibrillations in all cases. Moreover, at the EMG study, every patient presented with severe (complete) denervation in the facial nerve territory with a lack of motor unit action potential recruitment and nerve trunk inexcitability (direct stimulation at the tragus and evaluation of blink reflex responses).

The trigeminal motor component was clinically tested by palpating the masseteric region during chewing and by needle EMG in the ipsilateral masseter muscle to check its availability as a donor motor nerve.

The etiology of paralysis was iatrogenic in 29 (85.3\%) patients and trauma in $5(14.7 \%)$ patients.
Each patient underwent surgery performed by the senior author (F.B.) using the technique described earlier. The facial nerve trunk and masseteric nerve were joined together via interpositional nerve graft of the great auricular nerve in 20 patients. In the other 14 patients, a tract of the sural nerve was used, because those patients also received a sural nerve cross-face graft, with the aim of enabling a spontaneous smile.

Of the 34 patients, 24 also underwent 1 or more of the following ancillary procedures: eyebrow suspension (6 cases [17.6\%]); correction of lower eyelid ptosis and ectropion by mini-temporalis flap rotation (3 cases [8.8\%]) or fascia lata suspension (13 cases [38.2\%]); middle-third soft-tissue and upper lip suspension by fascia lata grafts (13 cases [38.2\%]) or mini-temporalis flap transfer according to a technique by Terzis and Olivares ${ }^{27}$ (6 cases [17.6\%]) or Labbé16 (2 cases [5.8\%]); lipofilling procedure to symmetrize the masseteric region (1 case [2.9\%]) or correct lip atrophy (7 cases [20.6\%]); and a mini-latissimus dorsi flap transfer to increase lower lip motility (1 case [2.9\%]).

No botulin toxin was injected into the healthy side to symmetrize static or dynamic appearance or into the affected side to treat synkinesis or spasm.

After surgery, each patient also underwent periodic clinical examination once the first postoperative contractions began. The patients were also instructed to advise the medical team when they recognized the first signs of mimetic muscle contraction.

Each patient underwent postoperative physiotherapy, from the time that recovery began up to 18 months postoperatively, and was followed up for up to 3 years. Our team physiotherapist treated the patients at the hospital or via Skype (for those who lived far away from Milan). The patients were also asked by the physiotherapist to exercise alone at least 3 times/day and encouraged to continue exercising even after physical therapy was completed. It is very important to exercise the affected part of the face, starting from a condition of symmetry at rest. We asked the patients to show their emotions, to make a grimace, and to smile with or without biting while trying to feel the amplitude of the movement. Further into the recovery period, they were told to check the execution of their movements by watching themselves in a mirror. All movements must be slow, allowing for selective muscle control; the patients were taught to gradually reduce the strength of the bite necessary to achieve mimetic muscle activation during the rehabilitative period.

Twelve months after the onset of postoperative facial activity, a panel of 3 physicians not involved in the surgery evaluated and graded the patients' facial paralysis according to the modified House-Brackmann scale, as suggested by the Sir Charles Bell Society proposal ${ }^{11}$ (Table 1). The classical House-Brackmann scale was conceived to classify facial paralysis or its spontaneous healing. Its use for classifying facial reanimation results is debatable, because some clinical details implicit in the aftermath, such as synkinesis and frontal branch paralysis, would unjustifiably downgrade the best results only because some goals could not be obtained by current facial reanimation techniques. ${ }^{11}$

Moreover, the classic House-Brackmann grading scale has rigid coupling of the grades for static symmetry and 
TABLE 1. Modified House-Brackmann grading scale system*

\begin{tabular}{lcccccc}
\hline \multicolumn{1}{c}{ Facial Zone } & Movement (\%) & Movement Score & Synkinesis (quantity) & Synkinesis Score & Total Score & Grade \\
\hline Eyebrow & 100 & 1 & None & 0 & 4 & I \\
\hline Eye & $>75$ & 2 & Slight & 1 & $5-9$ & II \\
\hline Nasolabial fold & $>50$ & 3 & Obvious & 2 & $10-14$ & III \\
\hline Oral & $<50$ & 4 & Disfiguring & 3 & $15-19$ & IV \\
\hline & Poor & 5 & & & $20-23$ & V \\
\hline Whole face & None & 6 & & & 24 & VI \\
\hline
\end{tabular}

* Four facial zones (eyebrow, eye, nasolabial fold, and oral) are graded according to percentages of movement and quantity of synkinesis. The sum of scores leads to grade (Roman numeral).

dynamic function. So, if a patient shows only little symmetry at rest but reaches optimal function of mimetic musculature, grading is difficult. With the use of the modified House-Brackmann scale, that problem is solved.

\section{Results}

Of the 34 patients, $91.2 \%$ showed visible activation of the mimetic musculature postoperatively; $8.8 \%$ did not show any improvement of facial nerve function after the surgical procedure. The average time of first contraction was 6.2 months (range 2-12 months) after surgery. Onset of the first mimetic musculature contractions was generally noticed at the corner of the mouth.

After 12 months from the first visible contraction, according to the modified House-Brackmann grading scale, $5.9 \%$ of the patients were classified as having Grade I function, $61.8 \%$ as having Grade II, $20.6 \%$ as having Grade III, $2.9 \%$ as having Grade IV, $2.9 \%$ as having Grade $\mathrm{V}$, and $5.9 \%$ as having Grade VI. Reaching Grade I on the modified scale is rare, because the synkinesis almost always registered in rehabilitated patients necessarily downgrades the results.

All the patients had to clench their teeth while smiling in the beginning. After 2-4 months of exercising with a physiotherapist, they had to think about smiling if they wanted to do it, but clenching was not necessary anymore. From 6 to 12 months after the first signs of mimicry reactivation, smiling became automatic for approximately half of the patients, which means that they did not need to think about smiling when they wanted to do so (e.g., when meeting a person). Spontaneity of smiling (laughing at a joke or while watching a funny movie) was observed in $3(18.8 \%)$ of the 16 patients who did not undergo adjunctive cross-face nerve grafting. Eleven $(61.1 \%)$ of the 18 patients who underwent adjunctive cross-face sural nerve grafting achieved spontaneous smiling (Fig. 3A-D, Videos 1 and 2).

VIDEO 1. Twelve months after surgery, the patient was able to produce a more symmetrical smile after a voluntary stimulus. Copyright Valeria Colombo. Published with permission. Click here to view.

VIDEO 2. Twelve months after surgery, spontaneous smiling enabled by activation of the cross-face nerve graft while watching a funny movie. Copyright Valeria Colombo. Published with permission. Click here view.

Surgical complications consisted of local infections in $2(5.9 \%)$ patients. Two other minor local infections developed after ancillary procedures. These infections were managed by antibiotic therapy and local rinsing with sa- line solution. One other patient (2.9\%) experienced postoperative bleeding that required an additional urgent surgery to ligate a superficial temporal artery rupture. No spasm of the mimetic musculature occurred in the postoperative period. The $24(70.6 \%)$ patients who underwent ancillary procedures to optimize their results showed a significant increase in static symmetry, which also led to a higher grade of symmetry while activating the facial musculature because the patients had the best starting position.

The duration of surgery was approximately 2 hours, and it was 60 minutes longer if cross-face nerve grafting was added. This surgery may reach 4.5 hours depending on the necessary combined techniques for the masseteric-facial nerve neurorrhaphy in selected patients, such as lower lid or nasolabial fold suspension with fascia lata grafting, lipofilling of the lips, or other cross-facial nerve grafts.

Patient data are summarized in Table 2.

\section{Discussion}

The mimetic musculature undergoes progressive atrophy as a consequence of facial nerve impairment. After a variable period of time (18-36 months), the atrophy becomes irreversible, and new musculature must be transplanted to reanimate the face. ${ }^{7,10}$ Thus, before 18 months after the onset of facial nerve impairment, a new neural stimulus must be provided. A reliable sign of reactivation of the mimetic musculature is the detection of fibrillation by EMG. ${ }^{28}$

In 1978, Spira ${ }^{26}$ provided the first report on the use of the masseteric nerve as a donor source for reconstructing a branch of the facial nerve, with a good result. More recently, Bermudez and Nieto ${ }^{1}$ reported a good outcome after microsurgical neurorrhaphy between the masseteric nerve and the zygomatic branch of an injured facial nerve. However, despite the significance of the functional rehabilitation shown in these reports, the importance of the results was limited because few facial branch reconstructions and case reports had been described. ${ }^{8}$

The renewed interest in the masseteric nerve as a new motor source in facial reanimation is a result of research by Zuker et al., ${ }^{18,34}$ who used it to reinnervate gracilis muscle flaps in patients affected by Moebius syndrome. Their operative technique, which has been clearly shown to be effective, has gradually become the current gold standard treatment for Moebius syndrome.

In 2012, Biglioli et al. ${ }^{6}$ described the first case series of 7 patients in whom total facial nerve rehabilitation was achieved by performing masseteric-facial nerve recon- 

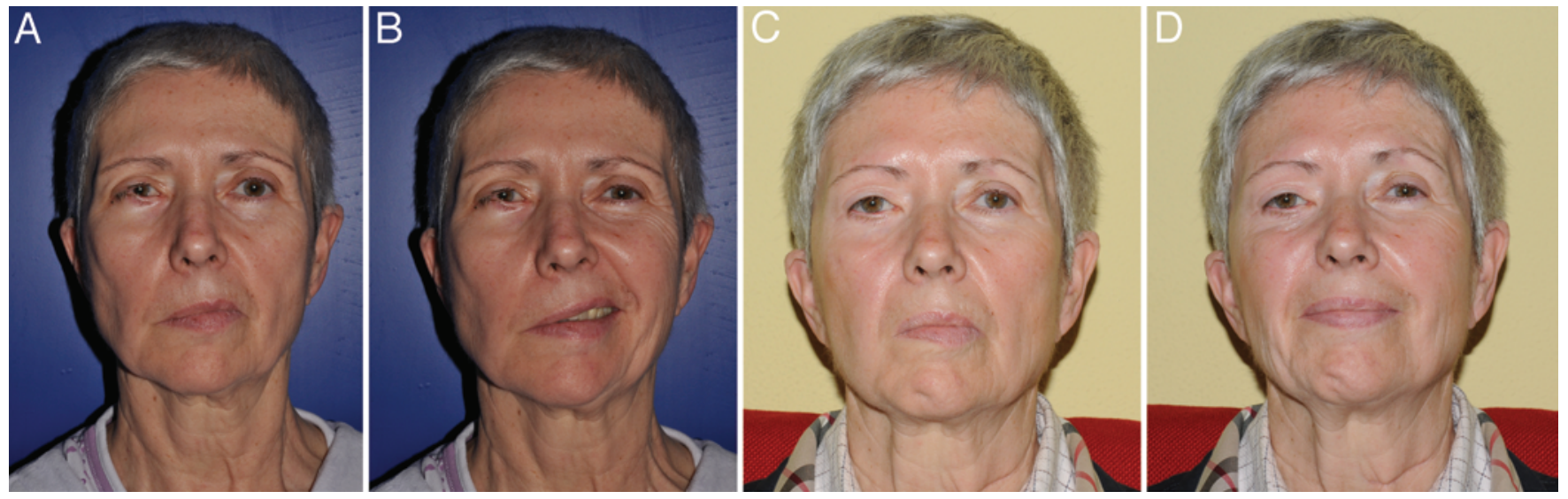

FIG. 3. A: Patient affected by complete facial paralysis as a consequence of acoustic neuroma surgery performed 12 months earlier. Lagophthalmos is hidden by a previous partial tarsorrhaphy. Note medium-grade ptosis of soft tissues at rest. B: Worsening of soft-tissue asymmetry while smiling. C: Patient 12 months after surgery with good symmetry of the face as a result of recovered muscle tone at rest and good orbital rim morphology after reversal of the tarsorrhaphy. D: Patient 12 months after surgery with nice symmetry of the face while smiling. Figure is available in color online only.

struction. The preliminary results were encouraging, and in our study, we used an extended version of this technique in a larger case series.

Clinical evaluation of the results, classified according to the modified House-Brackmann grading scale, indicated that the above-mentioned technique is a good treatment alternative for complete unilateral facial palsy and that it would be preferred over procedures that use other cranial nerves, such as the hypoglossal and spinal accessory nerves. ${ }^{11}$ Patients are able to effectively achieve satisfactory muscle contraction and avoid functional sequelae at the donor nerve site, which stands in contrast to results after hypoglossal-facial nerve or spinal-facial nerve neurorrhaphy. In fact, many authors have clearly documented that masseteric nerve deficits are not felt at all by patients. ${ }^{6,13}$

Hontanilla and Marré ${ }^{12}$ recently assessed facial reanimation by comparing anastomosis of the facial nerve to the masseteric and anastomosis using the hemihypoglossal nerve. They stated that masseteric-facial nerve neurorrhaphy results in a more impressive contraction restoration and a shorter recovery time.

Moreover, the movement required for a patient to activate the nerve (chewing) goes along much better with contralateral smiling than with the movements necessary to activate the hypoglossal (pushing the tongue against the teeth) or spinal (lifting the shoulders) nerves.

The importance of the nerve graft between the proximal stump of the masseteric nerve and the trunk of the facial nerve to achieve a tensionless neurorrhaphy must be underlined. In the present series, a great auricular nerve graft was harvested in 20 patients, whereas a sural nerve graft was used in 11 patients. Initially, we thought that the great auricular nerve was the best choice for grafting because of the low donor-site morbidity and the ease with which this nerve can be harvested. ${ }^{5,6}$ More recently, our preference changed to using the sural nerve because we decided to use a double-innervation technique (masseteric nerve plus the contralateral facial nerve, which requires a cross-facial sural nerve graft) to reanimate the paralyzed face. Therefore, a part of the sural nerve graft is already available to match the masseteric nerve to the facial nerve. The reason for switching to double innervation was the absence of spontaneous smiling in most patients (85\%) in whom the masseteric nerve alone was used. ${ }^{4}$ Several authors have observed that, in most patients, the motor branch of the trigeminal nerve cannot activate itself in response to a funny emotion. ${ }^{9}$ Actually, a research team in Toronto showed that spontaneous smiling was achieved by the masseteric motor nerve alone, but the sample consisted mainly of patients with Moebius syndrome who never had active facial nerve nuclei. ${ }^{18,34}$ Cerebral adaptation may have been different in those patients, and it was surely different from what we observed while our patients watched a funny video. $4,17,19,24,33$

Like many other authors, we agree on the need to coaptate contralateral facial nerve axons to obtain a fully natural and spontaneous smile. The main problem with the use of cross-face nerve grafting alone is the weakness of the axonal stimulus carried on it, which has led to frequent failure with the technique..$^{21,28}$

Thus, we decided to use a masseteric-facial nerve neurorrhaphy to guarantee a high grade of innervation for the paralyzed side of the face in our patients and to add a cross-face graft to obtain a natural and spontaneous smile. By doing so, $81.8 \%$ of the patients showed evidence of spontaneous smiling when watching a funny movie or hearing a joke. A similar technique was proposed recently by Bianchi et al. ${ }^{2}$

The cross-face grafting was accomplished on the uninjured side by performing an end-to-end neurorrhaphy between the sural nerve graft and the branch of the great zygomatic muscle, with the aim of conveying the correct stimulus in the patient while smiling. The distal neurorrhaphy, end-to-side to the branch for the great zygomatic muscle on the paralyzed side, provides the stimulus without hampering the already reconstructed facial nerve. ${ }^{31}$ Our impression is that the spontaneous stimulus of laughter arriving at the great zygomatic muscle on the pathological side is only partial because of the few axons crossing the face. In fact, they are few in number because they come from a tiny branch of the contralateral facial 
TABLE 2. Case series

\begin{tabular}{|c|c|c|c|c|c|}
\hline $\begin{array}{l}\text { Patient } \\
\text { No. }\end{array}$ & Age $^{*}(y r s)$, Sex & Timing (mos)† & Etiology & $\begin{array}{l}\text { Preop Grade } \\
\text { (HB) }\end{array}$ & Postop Grade (Modified HB) \\
\hline 1 & $39, F$ & 18 & & $\mathrm{VI}$ & ॥ \\
\hline 2 & $35, \mathrm{M}$ & 18 & Cerebellar astrocytoma removal & $\mathrm{VI}$ & II \\
\hline 3 & $32, \mathrm{~F}$ & 13 & Acoustic neurinoma removal & $\mathrm{VI}$ & II \\
\hline 4 & $40, M$ & 2 & Trauma & $\mathrm{VI}$ & $\|$ \\
\hline 5 & $54, \mathrm{M}$ & 18 & Acoustic neurinoma removal & VI & II \\
\hline 6 & $43, \mathrm{M}$ & 14 & Acoustic neurinoma removal & VI & IV \\
\hline 7 & $44, \mathrm{~F}$ & 16 & Acoustic neurinoma removal & VI & $\|$ \\
\hline 8 & $36, F$ & 11 & Trauma & $\mathrm{VI}$ & II \\
\hline 9 & $49, M$ & 18 & Acoustic neurinoma removal & VI & $\|$ \\
\hline 10 & $47, \mathrm{M}$ & 18 & Acoustic neurinoma removal & VI & III \\
\hline 11 & $21, F$ & 18 & Acoustic neurinoma removal & VI & III \\
\hline 12 & $17, \mathrm{M}$ & 6 & Trauma & $\mathrm{VI}$ & II \\
\hline 13 & $47, \mathrm{~F}$ & 18 & Acoustic neurinoma removal & $\mathrm{VI}$ & II \\
\hline 14 & $77, \mathrm{~F}$ & 18 & Acoustic neurinoma removal & $\mathrm{VI}$ & II \\
\hline 15 & $57, \mathrm{M}$ & 18 & Acoustic neurinoma removal & $\mathrm{VI}$ & II \\
\hline 16 & $62, \mathrm{~F}$ & 10 & Cholesteatoma & VI & III \\
\hline 17 & $40, M$ & 7 & Trauma & $\mathrm{VI}$ & II \\
\hline 18 & $43, \mathrm{M}$ & 4 & Trauma & $\mathrm{VI}$ & II \\
\hline 19 & $18, F$ & 17 & Bulbar astrocytoma removal & VI & III \\
\hline 20 & $53, \mathrm{~F}$ & 17 & Acoustic neurinoma removal & VI & II \\
\hline 21 & $42, F$ & 14 & Acoustic neurinoma removal & VI & $\mathrm{VI}$ \\
\hline 22 & $50, F$ & 18 & Acoustic neurinoma removal & VI & V \\
\hline 23 & $47, \mathrm{M}$ & 18 & Acoustic neurinoma removal & VI & III \\
\hline 24 & $58, F$ & 17 & Acoustic neurinoma removal & $\mathrm{VI}$ & $\mathrm{VI}$ \\
\hline 25 & $46, F$ & 8 & Acoustic neurinoma removal & $\mathrm{VI}$ & II \\
\hline 26 & $30, F$ & 12 & Acoustic neurinoma removal & $\mathrm{VI}$ & 1 \\
\hline 27 & $64, \mathrm{~F}$ & 13 & Acoustic neurinoma removal & $\mathrm{VI}$ & I \\
\hline 28 & $41, F$ & 12 & Acoustic neurinoma removal & $\mathrm{VI}$ & II \\
\hline 29 & $67, \mathrm{~F}$ & 18 & Acoustic neurinoma removal & $\mathrm{VI}$ & III \\
\hline 30 & $65, \mathrm{~F}$ & 8 & Acoustic neurinoma removal & VI & II \\
\hline 31 & $70, \mathrm{M}$ & 10 & Acoustic neurinoma removal & $\mathrm{VI}$ & III \\
\hline 32 & $50, F$ & 8 & Acoustic neurinoma removal & $\mathrm{VI}$ & II \\
\hline 33 & $56, \mathrm{~F}$ & 5 & Acoustic neurinoma removal & $\mathrm{Vl}$ & II \\
\hline 34 & $20, \mathrm{M}$ & 11 & Acoustic neurinoma removal & $\mathrm{Vl}$ & II \\
\hline
\end{tabular}

nerve, where they first must pass over a neurorrhaphy, and then they must regrow through a long nerve graft (further axonal loss) and cross a second (end-to-side) neurorrhaphy. Therefore, it is reasonable to believe that the axons finally reaching the great zygomatic muscle are not able to produce a convincing contraction of it. However, spontaneous smiling was absolutely visible in most of our patients. We think that the few axons crossing the end-to-side neurorrhaphy on the pathological side combine with the axons that do not overcome it to form a plaque and, when activated by a funny emotion, are able to "excite" those axons already present in the nerve branch of the great zygomatic muscle because of the masseteric-facial nerve neurorrhaphy. By this activation, the funny stimulus to the zygomat- ic muscle is able to make it produce a true spontaneous smile.

\section{Conclusions}

Masseteric-facial nerve neurorrhaphy is an efficient surgical technique for early facial reanimation that results in almost no morbidity, especially compared with traditional procedures, such as hypoglossal-facial nerve neurorrhaphy. Adding a cross-face nerve graft results in spontaneity of smiling in more than $80 \%$ of patients.

\section{Acknowledgments}

Prof. Antonio Michele Privitera is sincerely thanked by the 
authors because of his professional and logistic support to the present research.

\section{References}

1. Bermudez LE, Nieto LE: Masseteric-facial nerve anastomosis: case report. J Reconstr Microsurg 20:25-30, 2004

2. Bianchi B, Ferri A, Ferrari S, Copelli C, Salvagni L, Sesenna $\mathrm{E}$ : The masseteric nerve: a versatile power source in facial animation techniques. Br J Oral Maxillofac Surg 52:264269, 2014

3. Biglioli F, Colombo V, Pedrazzoli M, Frigerio A, Tarabbia F, Autelitano L, et al: Thoracodorsal nerve graft for reconstruction of facial nerve branching. J Craniomaxillofac Surg 42:e8-e14, 2014

4. Biglioli F, Colombo V, Tarabbia F, Autelitano L, Rabbiosi $D$, Colletti G, et al: Recovery of emotional smiling function in free-flap facial reanimation. J Oral Maxillofac Surg 70:2413-2418, 2012

5. Biglioli F, D'Orto, Bozzetti A, Brusati R: Function of the great auricular nerve following surgery for benign parotid disorders. J Craniomaxillofac Surg 30:308-317, 2002

6. Biglioli F, Frigerio A, Colombo V, Colletti G, Rabbiosi D, Mortini P, et al: Masseteric-facial nerve anastomosis for early facial reanimation. J Craniomaxillofac Surg 40:149-155, 2012

7. Biglioli F, Frigerio A, Rabbiosi D, Brusati R: Single-stage facial reanimation in the surgical treatment of unilateral established facial paralysis. Plast Reconstr Surg 124:124-133, 2009

8. Coombs CJ, Ek EW, Wu T, Cleland H, Leung MK: Masseteric-facial nerve coaptation-an alternative technique for facial nerve reinnervation. J Plast Reconstr Aesthet Surg 62:1580-1588, 2009

9. Faria JC, Scopel GP, Busnardo FF, Ferreira MC: Nerve sources for facial reanimation with muscle transplant in patients with unilateral facial palsy: clinical analysis of 3 techniques. Ann Plast Surg 59:87-91, 2007

10. Harii K, Ohmori K, Torii S: Free gracilis muscle transplantation, with microneurovascular anastomoses for the treatment of facial paralysis. A preliminary report. Plast Reconstr Surg 57:133-143, 1976

11. Henstrom DK, Skilbeck CJ, Weinberg J, Knox C, Cheney ML, Hadlock TA: Good correlation between original and modified House Brackmann facial grading systems. Laryngoscope 121:47-50, 2011

12. Hontanilla B, Marré D: Comparison of hemihypoglossal nerve versus masseteric nerve transpositions in the rehabilitation of short-term facial paralysis using the Facial Clima evaluating system. Plast Reconstr Surg 130:662e-672e, 2012

13. Hontanilla B, Marré D, Cabello A: Masseteric nerve for reanimation of the smile in short-term facial paralysis. Br $\mathbf{J}$ Oral Maxillofac Surg 52:118-123, 2014

14. House JW, Brackmann DE: Facial nerve grading system. Otolaryngol Head Neck Surg 93:146-147, 1985

15. Humphrey CD, Kriet JD: Nerve repair and cable grafting for facial paralysis. Facial Plast Surg 24:170-176, 2008

16. Labbé D: [Lengthening temporalis myoplasty.] Rev Stomatol Chir Maxillofac 103:79-83, 2002 (Fr)

17. Lifchez SD, Matloub HS, Gosain AK: Cortical adaptation to restoration of smiling after free muscle transfer innervated by the nerve to the masseter. Plast Reconstr Surg 115:14721482,2005

18. Manktelow RT, Tomat LR, Zuker RM, Chang M: Smile reconstruction in adults with free muscle transfer innervated by the masseter motor nerve: effectiveness and cerebral adaptation. Plast Reconstr Surg 118:885-899, 2006

19. Marré D, Hontanilla B: Brain plasticity in Möbius syndrome after unilateral muscle transfer: case report and review of the literature. Ann Plast Surg 68:97-100, 2012
20. Meyer RA: Nerve harvesting procedures. Atlas Oral Maxillofac Surg Clin North Am 9:77-91, 2001

21. O'Brien BM, Franklin JD, Morrison WA: Cross-facial nerve grafts and microneurovascular free muscle transfer for long established facial palsy. Br J Plast Surg 33:202-215, 1980

22. Pitty LF, Tator $\mathrm{CH}$ : Hypoglossal-facial nerve anastomosis for facial nerve palsy following surgery for cerebellopontine angle tumors. J Neurosurg 77:724-731, 1992

23. Reddy PG, Arden RL, Mathog RH: Facial nerve rehabilitation after radical parotidectomy. Laryngoscope 109:894899,1999

24. Rödel RM, Tergau F, Markus H, Laskawi R: Bilateral changes in cortical motor representation of the tongue after unilateral peripheral facial paralysis: evidence from transcranial magnetic stimulation. Ann Otol Rhinol Laryngol 113:951-955, 2004

25. Seddon HJ: The use of autogenous grafts for the repair of large gaps in peripheral nerves. Br J Surg 35:151-167, 1947

26. Spira M: Anastomosis of masseteric nerve to lower division of facial nerve for correction of lower facial paralysis. Preliminary report. Plast Reconstr Surg 61:330-334, 1978

27. Terzis JK, Olivares FS: Use of mini-temporalis transposition to improve free muscle outcomes for smile. Plast Reconstr Surg 122:1723-1732, 2008

28. Terzis JK, Tzafetta K: The "babysitter" procedure: minihypoglossal to facial nerve transfer and cross-facial nerve grafting. Plast Reconstr Surg 123:865-876, 2009

29. Vaughan ED, Richardson D: Facial nerve reconstruction following ablative parotid surgery. Br J Oral Maxillofac Surg 31:274-280, 1993

30. Venail F, Sabatier P, Mondain M, Segniarbieux F, Leipp C, Uziel A: Outcomes and complications of direct end-to-side facial-hypoglossal nerve anastomosis according to the modified May technique. J Neurosurg 110:786-791, 2009

31. Viterbo F, Amr AH, Stipp EJ, Reis FJ: End-to-side neurorrhaphy: past, present, and future. Plast Reconstr Surg 124 (6 Suppl):e351-e358, 2009

32. Yetiser S, Karapinar U: Hypoglossal-facial nerve anastomosis: a meta-analytic study. Ann Otol Rhinol Laryngol 116:542-549, 2007

33. Yildiz S, Bademkiran F, Yildiz N, Aydogdu I, Uludag B, Ertekin C: Facial motor cortex plasticity in patients with unilateral peripheral facial paralysis. NeuroRehabilitation 22:133-140, 2007

34. Zuker RM, Goldberg CS, Manktelow RT: Facial animation in children with Möbius syndrome after segmental gracilis muscle transplant. Plast Reconstr Surg 106:1-9, 2000

\section{Disclosures}

The authors report no conflict of interest concerning the materials or methods used in this study or the findings specified in this paper.

\section{Author Contributions}

Conception and design: Biglioli, Tarabbia. Acquisition of data: Rabbiosi, Giovanditto, Lozza. Drafting the article: Colombo. Administrative/technical/material support: Cupello, Mortini. Study supervision: Biglioli.

\section{Supplemental Information \\ Videos}

Video 1. https://vimeo.com/150680095.

Video 2. https://vimeo.com/150680094.

\section{Correspondence}

Valeria Colombo, San Paolo Hospital, Via Antonio di Rudiní, 8, Milan 20142, Italy. email: valeria.colombo84@hotmail.it. 